\title{
Attachment Theory: Developments, Debates and Recent Applications in Social Work, Social Care and Education
}

Published in the Journal of Social Work Practice online on $16^{\text {th }}$ December 2019

\begin{abstract}
Attachment theory may be considered controversial given that some of its foundational principles are contested. Not only this, it is currently being developed by insights from neuroscience, another perspective that academics have subjected to critique. Nevertheless, at the beginning of the twenty-first century in England and the United Kingdom in general, there has been a renewed interest in its explanation of child development, as well as its application in schools, social care settings and the practice of professionals such as social workers and teachers. This paper outlines the core principles of attachment theory, acknowledges some of the criticisms, then traces the ways in which the theory has been developed over time. The theory is then illustrated with a description of the ways in which it is being applied in the training of foster carers, the provision of support to adoptive parents and in the school environment.
\end{abstract}

Key words: adoption; attachment; children; education; fostering; social work Author: Prof. Elizabeth Harlow

Address: Faculty of Health and Social Care, University of Chester, Warrington Campus, Crab Lane, Fearnhead, Warrington, WA2 0DB, UK.

\section{Email: e.harlow@chester.ac.uk}

Tel: 07522546369

Orcid.org/0000-0001-5031-7485

Biographical details: Elizabeth Harlow PhD, BA, CQSW, FHEA is a Professor of Social Work at the University of Chester. She worked as a practitioner before beginning her academic career in 1988 . Focussing primarily on the organisation, management and delivery of services to children and their families, she has led research projects and evaluations and published her work over the last three decades. 


\section{Attachment Theory: Developments, Debates and Recent Applications in Social Work, Social Care and Education}

\section{Introduction}

In England in 2015 the National Institute of Health and Care Excellence provided guidance on the identification, assessment and treatment of attachment difficulties of children in the care system or at risk of entering the care system (NICE 2015). In the same year, the Department for Education provided advice on attachment disorder and the mental health of children in the school (DfE 2015). Whilst the principles of human attachment are informing policies and practice, the theory itself has been subjected to critique. This paper outlines the theoretical principles first proposed by Bowlby, responds to some of the critiques, but also draws attention to the various ways in which the original theory has been built upon. Examples of the ways in which the theory is being taken up in social work, social care and education are then provided.

\section{Attachment theory: definition and foundational principles}

Attachment is the strong, affectionate tie we have with special people in our lives that leads us to experience pleasure and joy when we interact with them and to be comforted by their nearness in times of stress. By the second half of the first year, infants have become attached to familiar people who have responded to their needs (Berk 2013: 428). 
The origins of attachment theory are attributed to John Bowlby, who was a psychoanalyst, and a member of the British group of object relations theorists. These theorists were developing an explanation of the way in which the relationship between the primary carer and the child created the structure and processes of the child's mind. Bowlby, however, shifted away from a focusing on psychoanalytic theory only, to linking it with knowledge gained from studying animals, and the practicality of care received by the human infant.

According to Bowlby, the infant's relationship with the parent begins as a set of innate signals that call the adult to the baby's side. Over time, a true affectionate bond forms, supported by new emotional and cognitive capacities as well as a history of warm, sensitive care (Berk 2013: 429).

From his research, Bowlby concluded that the primary caregiver has a particular role in providing the infant and child with a sense of safety: a secure base from which to thrive and flourish. According to the theory that was developed, there are four stages in the development of attachment:

- Preattachment phase (birth to 6 weeks)

- 'Attachment-in-the-making' phase (6 weeks to 6 to 8 months)

- 'Clear cut' attachment phase (6 to 8 months to 18 months to 2 years)

- Formation of a reciprocal relationship (18 months to 2 years and on).

(Berk 2013: 429). 
Bowlby explored, not only the building of this secure attachment, but also the loss and grief that is experienced by the infant when $s /$ he is separated from the mother (see Bowlby 1969; 1973; and 1980). Indeed, it was the implications of the motherinfant separation that initially mobilised Bowlby's interest. Bowlby went on to argue that the quality of attachment between the primary carer and infant created an 'internal working model' i.e. the mental model from which the child (and later adult) engages with the world. The suggestion being that, the quality of the earliest relationship(s) will inform the way in which the child (and later the adult) not only relates to others, but also explores and engages with life's opportunities. Howe (2011) elaborates on this when he traces attachment across the life course.

Whilst a secure attachment between the primary carer and child will provide a positive foundation for life, secure attachments are not possible for all. Mary Ainsworth developed a technique for analysing the quality of an attachment and concluded with a categorization of three types: secure; insecure avoidant; and insecure resistant or ambivalent (Ainsworth et al. 1978). This work was advanced by Main and Solomon (1986), who added a fourth category - insecure disorganized attachment, and Crittenden who refined the attachment categories still further (see Crittenden 1985). According to Howe (2011), Crittenden developed a lifespan developmental model of attachment (the Dynamic Maturational Model) which suggests that fear (for one's safety) does not give rise to disorganisation, but rather adaptation: that is, the child might oscillate between avoidant and ambivalent insecure patterns in an attempt to seek the greatest degree of security (Crittenden 2000a and 2000b cited in Howe 2011:159). Whilst researchers have refined the foundations of attachment theory, recent empirical findings and new theoretical insights have given rise to critiques, departures and altered emphases. An extensive 
body of literature has been created reflecting competing views and perspectives.

Before illustrating the application of attachment theory in practice, it is to this recent theoretical literature that attention is turned.

\section{Attachment theory: developments and debates}

Critics of attachment theory have challenged the way in which the theory appears to 'fix' human development: firstly, in terms of the early years of life and secondly, in terms of the categories of attachment. Firstly, Smith et al. (2017), by drawing on the empirical work of Rutter et al. (2007) contest the argument that a child's development is fixed by two years of age. Citing Rutter et al. they argue that the effect of insecure attachments early life can be reversed by positive later life experiences. However, Schofield and Beek (2018) insist that Bowlby did not stipulate irreversibility: instead, the 'internal working model' is indeed a 'working model' that is available for revision. The construction of an internal working model is linked to the primary carer as secure base. Whilst essential for survival in emergency situations in early childhood, the secure base allows for human development beyond this: it enables children to explore, engage in free play, and in consequence further their development (see Schofield and Beek 2005). Waters and Cummings (2000) reiterate that after infancy, social learning and cognitive development have influence also, which in turn impacts upon secure base expectations. All of this means that, not only is the internal working model available to change, but the potential for change lies in relationships beyond the initial dyad: multiple family relationships and events can be significant (Cummings and Davies 1996 cited in Waters and Cummings 2000). 
Secondly, Smith et al (2017) have criticised the fixity and pathologizing implications of Ainsworth's categorisation of attachment. However, whilst Ainsworth's original work still has currency, it has been built upon and refined, not only by Main and Solomon (1986) and Crittenden (1985; 2000a; and 200b) (as identified above), but also Duschinsky et al. (2015) who have shunned the imposition of rigid classification, and suggested that it may be more appropriate to think of attachment theory as ' $a$ psychology of the interplay of dynamic forces.' Fonagy et al. (2004) have reinterpreted attachment as relatively secure and relatively insecure. Furthermore, they argue that attachment has been re-envisioned '... from an emphasis on templates of relationships, fixed in early infancy, to a model that views attachment as the context provided by evolution for the development of interpersonal understanding' (Fonagy et al. 2004: 16-17).

Fonagy, along with a number of colleagues, has developed the theory of mentalization as a means of explaining the construction of selfhood and attachment. According to Fonagy, a sensitive carer will:

....respond with contingent and marked affective displays of their own experience in response to the infants subjective experience, thus enabling the child to develop second-order representations of his own subjective experiences (Fonagy 1998 cited in Fonagy and Allison 2014: 372).

Summarising the literature, Fonagy and Allison (2014) argue that the sensitivity of the carer will allow the child to experience being recognised as an 'intentional agent' as well as facilitate his/her building of 'cognitive, social-cognitive and emotionregulating capacity (p.373). Some of the relational behaviours that signal sensitivity include appropriate eye contact, communicational turn-taking and tone. Within this 
conducive environment the child develops epistemic trust in the carer. As the child grows and his/her social interactions extend beyond the carer, this enables the generalising of epistemic trust to others (where appropriate), which facilitates learning from the social environment.

By means of the concept of mentalization, Fonagy et al. (2004) have developed attachment theory in ways that that resolve the tensions between Bowlby's contribution and psychoanalysis: mentalization allows the mind to mediate our experience of the external world. As indicated above, as well as being crucial to our sense of self and agency, mentalization is linked to affect regulation, that is, our ability to regulate our affect states (Fonagy and Campbell 2015). It is proposed by these theorists that 'self-regulation as well as the ability to reflect on other minds are constructed capacities that have evolved (or not) out of the earliest relationships' (Fonagy et al. 2004: 5).

Whilst relational interaction in the social domain is the main focus of the account of child development provided by Fonagy and the colleagues with whom he writes, they also acknowledge that evolution, genes, hormones and neural functioning make a contribution to the way in which this occurs. In contrast to these theorists, Porges (2011) prioritises an evolutionary perspective and the neurophysiological components of child and parent interaction that correspond with attachment theory. Given this contrast, and in order to provide another example of the theoretical developments that have occurred, Porges' contribution is summarised below. Porges emphasises the significance of risk to human survival and the way in which it is assessed (which he calls neuroception). His polyvagal theory concerns the individual's neurobiological defensive response to risk (such as fight, flight or freeze) and technological innovation, such as functional magnetic resonance imaging (fMRI), 
has enabled researchers to explore this physiologically. According to this theory, if a secure base is not communicated by the primary carer (by means of facial interaction, for example), then the infant's neuroception may be impaired: that is, he or she may not develop the required sophistication to assess risk in the social environment, which may lead to a heightened sense of fear and inappropriate defensive reactions. In extreme cases this may lead to psychpathology. For Porges, the consequence of the theory means that individuals with an insecure attachment requires intervention in the social domain (externally), but also individually (internally): that is, a secure base should be provided (in foster care or the school environment, as discussed below, for example), but in addition he suggests 'We can also intervene directly with children, exercising the neural regulation of the social engagement system and encourage social behaviour' (Porges 2011: 19). Intervention may include forms of music therapy.

Porges' theory is complex and outlined here in only the simplest of terms. There are many criticisms, however. For example, there is no clear consensus on the value of evolutionary psychology, the perspective which informed Bowlby's work, but which is now revived and emphasised in Porges' thesis. This is because theory from this perspective can only ever be post-hoc and claims cannot be proved (Glassman and Hadad 2013). Furthermore, evolutionary psychology depends on biology and the biological intricacies of brain functioning are not well understood. Rose and Rose (2016), critical of the overstatement of claims for neuroscience point out that there is still no one theory of the brain, and despite the advances in technology, it is still inadequate to the enormity of the task that is at issue. In general support of this principle, Glassman and Hadad make the point that there are about '...10 billion neurons in the cortex of the brain alone, which are interconnected in manifold ways. 
In addition, there are countless chemical interactions involving neurotransmitters, hormones and neuropeptides ...' (Glassman and Hadad 2013: 88). Critics such as Rose and Rose (2016) argue that fMRI scans do not give rise to causal scientific truths (as some might claim), but interpretations that suggest correlations. Unfortunately, the way in which some scientists have reduced behaviour to nothing more than the biology of the brain, together with the oversimplification and popularisation of neuroscience in the media, some authors (such as Gabriel 2017) and professionals (such as psychoanalysts) have shunned it as a serious contributor to our understanding of human development (Fotopoulou 2012).

In constructing a theory of human development that involves attachment between the infant and primary carer as key, all of the three theorists discussed above (Bowlby, Fonagy and Porges), have emphasised the biological component of human attachment to a greater or lesser extent: put another way, all three have offered a biopsychosocial account. However, it might be argued that for Bowlby and Fonagy the emphasis is on the psychosocial construction of, and interpretative function of the 'mind', whilst for Porges the biological materiality of the body and neural process is ascendant. Underpinning these theoretical contributions lie the philosophical debates concerning the mind-body dualism. Debates that have been taken up by Fotopoulo (2012).

Fotopoulou (2012) has articulated the projects of neuropsychoanalysis and neurophilosophy which aim to overcome the mind-body dualism: for the mind-body dualism to be understood, the 'mind' has to be seen to be as real as the brain and that both subjective experiences as well as brain states have to be appreciated. Theoretical innovations which attempt to overcome the mind-body dualism are applauded by academics such as McKenzie and Roberts (2017). These debates 
suggest that theories relating to human attachment are the result, not only of technological innovation (such as fMRI), but philosophical considerations also. In sum, taking into account the expansion of theoretical insights (not all of which could be covered here), Schore and Schore (2008) suggest that there has emerged a new emphasis on the affect regulation or the regulation of the emotions:

... the concept of regulation theory as an amalgam of Bowlby's attachment theory, updated internal object relations theories, self-psychology and contemporary relational theory all informed by neuroscience and infant research. This is a profoundly developmental approach. We understand any individual's personal trajectory of emotional growth, including his/her unconscious, to be facilitated or inhibited by his/her family and culture (Schore and Schore 2008:17).

Irrespective of the preferred explanation or point of emphasis, human attachments and the associated implications, are seen as crucial to the practice of professionals tasked with ensuring and enhancing the developmental wellbeing of children. It is to some of the practical applications of attachment and corresponding theories that attention is now turned.

\section{Attachment theory and its application in social work, social care and education}

Although there has, to some extent, been a departure from a simplistic and rigid categorisation of attachment types, an extreme version of an insecure attachment has now been recognized as a disorder by the National Institute of Health and Care Excellence (see NICE 2015). However, NICE has made clear that the term attachment disorder should only be used when a young person has been formally 
diagnosed by qualified professionals in accordance with the established criteria. Furthermore, social workers have been advised to use the term 'attachment' with caution and that in most instances, the more general term 'relationship' might suffice (Shemmings 2018). Nevertheless, since Bowlby's initial contribution, the principles of human attachment have been important components of social work. Along with associated psychodynamic theory, it is relevant to relationship-based practice with all service users (see Ruch 2018). Here, however, attention will be given to work with children, young people and their families. As indicated above, children and young people who have experienced phenomena such as loss and grief, abuse and neglect, are less likely to have benefitted from sustained secure attachments: although not inevitably so, they are more likely to be insecure and anxious. For fostered and adopted children and young people, continuity, an understanding environment, and one or more relationships that provide a secure base become essential if previous difficulties are to be surmounted. These principles are important in their home, but also in their school. What follows is an attempt to illustrate the way in which these principles are being promoted through the training and/or support of foster carers, adopters and school staff members.

By means of longitudinal research on children (in middle childhood or early adolescence) growing up in foster care, Schofield and Beek (2005) have theorised the day-to-day construction of an emotionally secure base. The researchers identified five interconnected and mutually reinforcing dimensions of the care provided by the foster carers. These dimensions, together with examples of parenting and their children's behaviours, are indicated in brief. 


\section{Promoting trust in availability}

The carers in the project demonstrated a focus on the child's needs, even in his/her absence, that was seen as akin to maternal preoccupation (Winnicott 1965). In addition to thinking about the ways in which the child's problems might be solved, thought was given to positive contribution the child was making to the family. In this way, the carer was holding the child in mind. Physical care was also provided. Even adolescent children enjoyed practical care such as hair washing or affectionate hand holding.

\section{Promoting reflective function}

The carer's ability to think flexibly assists the child to do the same and carers can help children to make sense of their own minds as well as the minds of others (Fonagy and Target 1997). This is important in developing resilience as well as social and interpersonal competence. Ongoing conversations about day-to-day emotions took place and the children benefitted from feeling understood and accepted.

\section{Promoting self-esteem}

Positive parenting conveys to children their unconditional acceptance. This occurs by means of loving gestures, kind words and praise. Children learn to feel valued for who they are. Hence, failures can be tolerated and help sought when required. The parents in Schofield and Beek's study spoke with pride about the children's achievements and the characteristics with warmth. A growing sense of self-esteem was demonstrated by the children as they took part in classroom activities, became more outgoing and acknowledged their strengths.

Promoting autonomy/self-efficacy 
Infants express their needs and sensitive parents react appropriately, hence there develops the idea that a behaviour leads to a positive response, but also that there is the capacity for control over the environment. Parents who are available, allow the child to explore confident in the knowledge that they will still be available on return. However, as the child matures, there is recognition of the parent's needs, so develops co-operation and negotiation. Foster children may have had to be too independent in the past and been too powerful. Alternatively, if birth parents had been too controlling, they may not have had the opportunity to exercise independence. Foster carers' in the Schofield and Beek study encouraged children to be independent in ways that related to the child's age and ability, for example, encouraging a child to choose which clothes to wear or facilitating in the achievement of homework rather than undertaking the homework on the child's behalf. The children demonstrated independence by taking up hobbies, either solitary hobbies or those that were shared with others. Most of the behaviours involved negotiation and compromise.

\section{Promoting family membership}

Becoming a member of a family means complying with expectations and embracing the norms and values. Being part of a family provides an anchorage and emotional solidarity over the life course. The norms and values were played out by means of rituals, such as the giving and receiving of cards and gifts. Carers and their extended family included the fostered children in these rituals and over time the children talked about their home rather than their placement.

This model, which acknowledges the biopsychosocial foundations of attachment theory, emphasises the psychosocial content and has been used widely to train prospective foster carers for their future role (see Schofield and Beek 2016). The 
model is relevant in preparing adoptive parents for their new role. In order to help facilitate the success of the adoption, training that helps adoptive parents understand that, despite their efforts to build their relationship, the children may still exhibit troubled behaviour (McNeish and Scott 2013: 29). However, from the autoethnographic account provided by Mackenzie and Roberts (2017), in providing training for adoptive parents, social workers and clinical psychologists are also emphasising the importance of affect regulation and drawing on theories that are influenced by evolutionary theory and neuroscience in general. As a result of being immersed in training, support delivered from this perspective, and the recommended reading materials, Mackenzie and Roberts reflected on parenting in the following way:

Encountering difficult behaviour and overwhelming feelings, we learnt to ask: is there some visual trigger, olfactory memory or metabolic state (blood sugar, heart rate, cortisol) pointing to other more dangerous places or times something like a body memory - at play here? Perhaps re-mapping those mundane or shocking events - he spat in my face; she deliberately smashed the bowl - through ethological or biochemical processes might bring parents to engage differently to the child or between the child and themselves at that moment, and thereby help both the child and themselves to remain anchored in the present (which is less frightening or dangerous in objective terms) (Mackenzie and Roberts 2017: 137).

Recognising the development away from the reliance on Bowlby's original formulation only and the recent emphasis on 'brain-based parenting' (which is more aligned with the work of Porges, as summarised above), Mackenzie and Roberts noted the ad hoc approach that was taken to theory: that is, with the intention of 
offering a positive intervention professionals did not refer to original research, clinical papers or promote theoretical coherence, but articulated explanations of attachment, child development and behaviour on a pragmatic basis. Such an approach is replicated in the popular 'how-to' books that were recommended as forms of assistance for the adoptive parents (Mackenzie and Roberts 2017).

A Centre for Adoption Support (CfAS) was established in the northwest of England in 2013. An evaluation of its construction and performance showed that attachment theory influenced the form and content of the services delivered (see Author et al. 2015; Author 2018). In particular, the work of Dan Hughes $(1999 ; 2004)$ had been embraced. Hughes, a psychotherapist, has made a particular contribution to knowledge and practice by applying the principles of attachment theory to the needs of adoptive families. He aims to address the emotional pain that an adopted child may have experienced. Such experience inhibits the building of the child's affect regulation with the consequence of behavioural and relational problems. According to Rushton and Dance (2002), adoptive parents reported that children's 'weak return of affection or rejection, persistent non-compliance, violence and aggression' was particularly difficult to deal with. Hughes emphasises verbal and non-verbal attunement in the building of the new relationship between the child and his/her adoptive parents. The CfAS social workers had attended Hughes' training on Dyadic Developmental Psychotherapy (see Hughes et al. 2015). This training appeared to inform and enhance the relationship-based social work that was being undertaken. When talking about the service she had received from CfAS, an adoptive mother (with the pseudonym of Mrs Black) said that she would have welcomed such support from the start of the time her children had been placed with her: 
Mrs Black: Well, it doesn't have to be a therapist. [It] could be a therapeutic social worker. Somebody like [names social worker from CfAS] who understands attachment, who is emotionally in tune, that can be a listening ear and say, 'Have you tried strategies?'. Some practical advice as well as that sort of listening ear, so you don't feel so isolated (T1:6) (Author et al. 2015: 31).

From the CfAS research, it appeared that many adoptive parents needed support in managing daily life at home, but they felt this was impacted by their child's experience in school. They felt that improvements could be made if the emotional needs of their children were appreciated by school staff. This sentiment was echoed in research conducted by Adoption UK:

Many respondents felt that staff and education professionals should be trained in issues of trauma and attachment, and that there needs to be a better understanding of the needs of adopted children (Pennington undated:35)

Social workers at the CfAS were responding to the concerns of adopted parents by working directly with school staff members to create an environment that reduced the anxieties of individual children: i.e. tailored packages of support were introduced. In addition, however, training on attachment theory was made available for the whole school (see also Adoption UK undated).

Attachment disorder is now acknowledged in the Department for Education's advice on mental health and behaviour in school (DfE 2015). However, interest in human attachments and their significance in the school environment is broader that the topic 
of health (see for example, Clements 2013; Geddes 2006; Marshall 2014; Phillips 2007; Ubha and Cahill 2014; and Webber 2017). As with social work, as indicated above, the practice literature relating to education is often eclectic in approach. For example, Rose and Gilbert (2017) refer to the work of Bowlby as well as Porges. Irrespective of this eclecticism, however, contributors in general argue that the implementation of attachment principles in school can improve the general wellbeing of students and in consequence their performance (see Bergin and Bergin 2009). Also, it is argued that by helping school staff understand and respond to disruptive behaviour as evidence of emotional insecurity, the rate of exclusions can be reduced. There are three main approaches to the implementation of attachment principles in school. Firstly, children who are struggling to regulate their emotions may be offered emotion coaching (see Bombèr and Hughes 2013; Gus and Wood 2017). Secondly, efforts are made to develop the awareness of all school staff members in order that they might reflect on the meanings of behaviour (for example, in the light of insights concerning fear and anxiety) with the ambition that their relationships with all students are enhanced. This relates closely to the third approach which emphasises the functioning of the whole school (see Bergin and Bergin 2009). Importantly, it is the responsibility of school leaders to encourage a warm socioemotional climate and a culture of respect. In order to stimulate a sense of security, continuity of people and place is beneficial, and advantage may be gained when essential transitions (across years and schools) are facilitated. Small schools that are embedded within their communities are more likely to encourage student bonding, and inclusive extra-curricular activities are helpful with this. In short, the school itself should become a secure base. 


\section{Conclusion}

Decades have elapsed since Bowlby developed his theory of attachment. Its popularity has fluctuated and over recent times it has been reinvigorated. However, from the discussion above, it can be seen that it has been developed and integrated with a range of new theoretical and philosophical insights. It might be argued that there is no longer one 'attachment theory', but that over time there have evolved a number of theoretical explanations of human attachment. Whilst each of these theoretical explanations may take into account biology, psychology, and social relationships - making the explanation biopsychosocial - each explanation may emphasise different elements. However, when psychologists, social workers and associated professionals inform their work with theories of attachment (which may or may not refer to neuroscience), like cultural and social theorists, they may do so in an eclectic manner (see Mackenzie and Roberts (2017). Whilst there is a risk that an emphasis on the biology of 'brain science' becomes collapsed with 'brain damage', respondents in the CfAS study as well as Mackenzie and Roberts found that as adoptive parents, their experience of training and support provided by professionals to be helpful. Being provided with an explanation of their child's challenging behaviour, reassurance that change could occur, together with suggestions for making this happen, brought welcome relief. Nevertheless, theories of attachment do not constitute a panacea and Scott (2018) warned against their over-use as an explanatory tool: that is, it would be possible to misdiagnose the needs of a child if there was an automatic reliance on the principles of attachment. Similarly, some therapies associated with attachment and/or 'brain science' may not be evidentially legitimate: it is not possible to 'fix' specific components of the brain 
and it is better to pursue conventional therapies that have been thoroughly evaluated and tested over time.

Finally, it may be argued that focusing on attachment highlights the child and parent/carer relationship with the consequence that essential considerations concerning the wider community are cast into shadow. However, Schofield and Beek (2018) embed their emphasis on relationships within Bronfenbrenner's (1979) ecological model of growth and human development. Furthermore, the social workers who are working with the staff members of schools are acting within the terms of this model. Importantly, the emphasis on whole school change shifts attention away from specific parents, carers or children, and encourages systemic organisational change that aims to benefit all concerned.

\section{Acknowledgements}

Gratitude is extended to all those who supported the writing of this paper. These include: Alan Wood; Kate Fillingham; Karen Izod; Hilary Rose, Steven Rose, Fiona Sheikh; and the Alex Timpson Trust.

\section{References}

Adoption UK (undated) Bridging the Gap: Giving Adopted Children and Equal Chance in School Banbury: Adoption UK www.adoptionuk.org/Handlers/Download.ashx?IDMF=e460b99a-4ebb-4348-bd23$\underline{64 a 50 d 747901}$ (accessed 23 ${ }^{\text {rd }}$ May 2019) 
Ainsworth, M., Blehar, M., Waters, E. and Wall, S. (1978) Patterns of Attachment: A Psychological Study of the Strange Situation Hillsdale, NJ: Erlbaum.

Bergin, C. and Bergin, D. (2009) Attachment in the Classroom Educational Psychology Review, 21: 141-170.

Berk, L. E. (2013) Child Development London: Pearson (9 ${ }^{\text {th }}$ ed).

Bombèr, L. M. and Hughes, D. A. (2013) Settling to Learn. Settling Troubled Pupils to Learn: Why Relationships Matter in School London: Worth Publishing.

Bowlby, J. (1969) Attachment and Loss: vol. 1: Attachment London: Howgarth Press.

Bowlby, J. (1973) Attachment and Loss: vol. 2: Separation: Anger and Anxiety London: Howgarth Press.

Bowlby, J. (1980) Attachment and Loss: vol. 3: Loss: Sadness and Depression London: Howgarth Press.

Bronfenbrenner, U. (1979) The Ecology of Human Development: Experiments by Nature and Design Cambridge MA: Harvard University press.

Clements, J. (2013) A Good practice Guide for Schools. Understanding and Meeting the Needs of Children who are Looked After, Fostered or Adopted or Otherwise Permanently Placed London: Pac 
Crittenden, P. M. (1985) Social Networks, Quality of Parenting, and Child Development Child Development, 56:1299-313.

Crittenden, P.M. (2000a) 'A Dynamic-Maturational Model of the Function, Development and Organization of Human Relationships' in Mills, R.S.L. and Duck, S. (eds) Developmental Psychology of Personal Relationships Chichester: Wiley, pp.199-218.

Crittenden, P.M. (2000b) 'A Dynamic-Maturational Exploration of the Meaning of Security and Adaptation: Empirical, Cultural and Theoretical Considerations', in Crittenden, P.m. and Claussen, A.A. (eds) The Organization of Attachment Relationships: Maturation, Culture and Context, New York: Cambridge University Press, pp.343-353.

Cummings, E. M. and Davies, P. (1996) Emotional Security as a Regulatory Process in Normal Development and the Development of Psychopathology, Development and Psychopathology 8: 123-139.

DfE (Department for Education) (2015) Mental Health and Behaviour in Schools. Department Advice for School Staff www.gov.uk/government/publications.

Duschinsky, R., Greco, M. and Soloman, J. (2015) The Politics of Attachment: Lines of Flight with Bowlby, Deleuze and Guattari Theory Culture and Society 32(7-8); 173195. 
Fonagy, P. (1998). An attachment theory approach to treatment of the difficult patient. Bulletin of the Menninger Clinic, 62: 147-169.

Fonagy, P. and Allison, E. (2014) The Role of Mentalizing and Epistemic Trust in the Therapeutic Relationship, Psychotherapy, 15(3); 372-380.

Fonagy, P. and Campbell, C. (2015) Attachment and Mentalizing, in Elliot, A. and Prager, J. (eds) The Routledge Handbook of Psychoanalysis in the Social Sciences and Humanities London: Routledge, pp.115-131.

Fonagy, P. Gergely, G., Jurist, E.L. and Target, M. (2004) Affect Regulation, Mentalization, and the Development of the Self London: Karnac.

Fonagy, P. and Target, M. (1997) Attachment and Reflective Function: their Role in Self-organisation, Development and Psychopathology, 9, 679-700.

Fotopoulou, A. (K), (2012) 'The History of Progress of Neuropsychoanalysis' in Fotopoulou, A., Pfaff, D., Conway, M.A. (eds) From the Couch to the Lab: Trends in Psychodynamic Neuroscience Oxford: Oxford University Press, p.12-24.

Gabriel, M. (2017) I am not a Brain Cambridge: Polity Press.

Geddes, H. (2006) Attachment in the Classroom. The Links Between Children's Early Experience, Emotional Well-being and Performance in the Classroom London: Worth Publishing 
Glassman, W. E. and Hadad, M. (2013) Approaches to Psychology London: McGraw-Hill (6 $6^{\text {th }}$ edition)

Gus, L. and Wood, F. (2017) ‘Emotion Coaching' in Colley, D. and Cooper, P. (eds) Attachment and Emotional Development in the Classroom. Theory and Practice London: Jessica Kingsley Publishing, pp.83-99.

Harlow, E. (2018) Defining the Problem and Sourcing the Solution: a Reflection on Some of the Organisational, Professional and Emotional Complexities of Accessing Post-adoption Support, Journal of Social Work Practice, 33(3):269-280.

Harlow, E. Mitchell, A., Doherty, P. and Moran, P. (2015) Constructing and Delivering Services of Support: An Evaluation of the Northwest Post-placement Adoption Support Service (2) Chester: University of Chester.

Howe, D. (2011) Attachment across the Lifecourse. A Brief Introduction Basingstoke: Palgrave Macmillan.

Hughes, D. A. (1999) Adopting Children with Attachment Problems, Child Welfare, LXXVIII(5): 541-560.

Hughes, D. (2004) An Attachment-based Treatment of Maltreated and Young People, Attachment and Human Development, 6(3): 263-278. 
Hughes, D., Golding, K. and Hudson, J. (2015) Dyadic Developmental Psychotherapy: The Development of the Theory, Practice and Research Base, Adoption and Fostering, 39(4): 356-365.

Mackenzie, A. and Roberts, C. (2017) Adopting Neuroscience: Parenting and Affective Indeterminacy Body and Society 23(3): 130-155.

Main, M. and Solomon, J. (1986) ‘Discovery of a New, Insecuredisorganized/disoriented Attachment Pattern', in Yogman, M. and Brazelton, T. B. (eds) Affective Development in Infancy Norwood, NJ: Ablex, pp. 95-124.

Marshall, N. (2014) The Teachers Introduction to Attachment. Practical Essentials for Teachers, Carers and School Support Staff London: Jessica Kingsley.

McNeish, D. ad Scott, S. (2013) What Works in Achieving Adoption for Looked After Children: An Overview of Evidence for Coram/Barnardo Partnership, www.coram.org.uk/resource/what-works-achieving-adoption-looked-after-childrenoverview-evidence-corambarnardos

NICE (National Institute of Health and Care Excellence) (2015) Children's Attachment: Attachment in Children and Young People who are Adopted from Care, in Care or at High Risk of Going into Care, www.nice.org.uk/guidance/ng26. 
Pennington, E. (undated) It Takes a Village to Raise a Child: Adoption UK Survey on Adoption Support Banbury: Adoption UK.

Phillips, R. (2007) The Need for Information on How Attachment Difficulties of Adopted and Looked After Children Affect their Schooling Adoption and Fostering 31(3): 28-38.

Porges, S. W. (2011) The Polyvagal Theory: New Physiological Foundations of Emotions, Attachment, Communication and Self-regulation London: W.W.Norton and Company.

Rose, H. and Rose, S. (2016) Can Neuroscience Change our Minds? Cambridge: Polity Press.

Rose, J. and Gilbert, L. (2017) 'Attachment Aware Schools', in Colley, D. and Cooper, P. (eds) Attachment and Development in the Classroom: Theory and Practice London: Jessica Kingsley Publishers, pp: 65-81.

Ruch, G. (2018) 'The Contemporary Context of Relationship-Based Practice' in Ruch, G., Turney, D., and Ward, A. (eds) Relationship-Based Social Work London: Jessica Kingsley Publishing, $2^{\text {nd }}$ edition, pp.19-35.

Rushton, A. and Dance, C. (2002) Adoption Support Services for Families in Difficulty. A Literature Review and UK Survey London: British Association of Adoption and Fostering. 
Rutter, M., Beckett, C., Castle, J., Colvert, E., Kreppner, J., Mehta, M., Stevens, S., Sonuga-Barke, E. (2007) Effects of Profound Early Institutional Deprivation: An Overview of Findings from a UK Longitudinal Study of Romanian Adoptees, European Journal of Development Psychology, 4(3): 332-350.

Schore, J. R. and Schore, A. N. (2008) Modern Attachment Theory: the Central Role of Affect Regulation in Development and Treatment, Clinical Social Work Journal, 36(1): 9-20.

Scott, S. (2018) Presentation made at the conference 'Realising our Vision for Adoption in the UK: Working in Partnership to Deliver Excellent Services Nationwide', a Public Policy Exchange Symposium held at the Strand Palace Hotel, London, UK on $6^{\text {th }}$ June.

Schofield, G. and Beek, M. (2005) Providing a Secure Base: Parenting Children in Long-term Foster Family Care, Attachment and Human Development, 7(1): 3-26.

Schofield, G. and Beek, M. (2016) The Secure Base Model. Promoting Attachment and Resilience in Foster Care and Adoption London: CoramBAAF.

Schofield, G. and Beek, M (20018) Attachment Handbook for Foster Care and Adoption London: CoramBAAF (2 ${ }^{\text {nd }}$ edition). 
Shemmings, D. (2018) Why Social Workers Shouldn't Use 'Attachment' in their Records and Reports, Community Care, June 28.

www.communitycare.co.uk/2018/06/28/social-workers-shouldnt-use-attachmentrecords-reports/ (accessed 2/5/19).

Smith, M., Cameron, C. and Reimer, D. (2017) From Attachment to Recognition for Children in Care, British Journal of Social Work, 47(6): 1606-1623.

Ubha, N. and Cahill, S. (2014) Building Secure Attachments for Primary School Children: a Mixed Methods Study, Educational Psychology in Practice, 30(3): 272292.

Waters, E. and Cummings, E. M. (2000) A Secure Base from Which to Explore Close Relationships, Child Development, 21(1):164-172.

Webber, L. (2017) A School's Journey in Creating a Relational Environment which Supports Attachment and Emotional Security, Emotional and Behavioural Difficulties, 22(4): 317-331.

Winnicott, D. (1965) The Maturational Process and the Facilitative Environment New York: International Universities Press. 